\title{
NHL-BFM-95 Regimen
}

National Cancer Institute

\section{Source}

National Cancer Institute. NHL-BFM-95 Regimen. NCI Thesaurus. Code C67216.

A modified version of the NHL-BFM 90 regimen, employing a different methotrexate dosing schedule, used for the treatment of localized aggressive forms of childhood B-cell lymphoma, including lymphoblastic lymphoma. 